\title{
Pathogens and insect herbivores drive rainforest plant diversity and composition
}

Robert Bagchi $^{1,2}$, Rachel E. Gallery ${ }^{1,3}$, Sofia Gripenberg ${ }^{1,4}$, Sarah J. Gurr ${ }^{5,6}$, Lakshmi Narayan $^{1}$, Claire E. Addis ${ }^{1}$, Robert P. Freckleton ${ }^{7}$ and Owen T. Lewis ${ }^{1}$

${ }^{1}$ Department of Zoology, University of Oxford, South Parks Road, Oxford OX1 3PS, $U K$

${ }^{2}$ Ecosystem Management Group, Institute of Terrestrial Ecosystems, ETH Zürich, Universitätstrasse 16, 8092 Zürich, Switzerland

${ }^{3}$ School of Natural Resources and the Environment, University of Arizona, Tucson, AZ 85721, USA

${ }^{4}$ Section of Biodiversity and Environmental Research, Department of Biology, University of Turku, 20014, Turku, Finland

${ }^{5}$ Department of BioSciences, Geoffrey Pope Building, University of Exeter, Exeter EX4 4QD, UK

${ }^{6}$ Department of Plant Sciences, University of Oxford, South Parks Road, Oxford OX1 $3 R B, U K$.

${ }^{7}$ Department of Animal and Plant Science, University of Sheffield, Western Bank, Sheffield, S10 2TN, UK. 
Tropical forests are important reservoirs of biodiversity ${ }^{1}$, but the processes that determine this diversity remain poorly understood ${ }^{2}$. The Janzen-Connell hypothesis $^{3-4}$ suggests that specialised natural enemies such as insect herbivores and fungal pathogens maintain high diversity by elevating mortality when plant species occur at high density (negative density dependence; NDD). NDD has been detected widely in tropical forests ${ }^{5-9}$, but the prediction that NDD caused by insects and pathogens plays a community-wide role in maintaining tropical plant diversity remains untested. Using manipulative exclusion experiments we show that changes in plant diversity and species composition are caused by fungal pathogens and insect herbivores. Plant species richness increased across the seed to seedling transition, suggesting a strong recruitment filter at this $\operatorname{stage}^{10}$. Treating seeds and young seedlings with fungicides significantly reduced the diversity of the seedling assemblage, consistent with the Janzen-Connell hypothesis. While suppressing insect herbivores using insecticides did not alter species diversity, it greatly increased seedling recruitment and caused a marked shift in seedling species composition. Overall, seedling recruitment was significantly reduced at high seed densities and this NDD was greatest for the most abundant species. Suppressing fungi removed the negative effects of density on recruitment, confirming that the diversity-enhancing effect of fungi is mediated by NDD. Our study provides an overall test of the Janzen-Connell hypothesis and demonstrates the crucial role that insects and pathogens play both in structuring tropical plant communities and in maintaining their extraordinary diversity. 
Understanding the mechanisms that allow species to coexist in natural ecosystems remains one of the most enduring questions in community ecology. The key challenge is to identify how competitive exclusion is prevented, particularly where large numbers of species share similar resource requirements ${ }^{11}$. This question has special relevance to tropical forest plant communities, which can have exceptional species richness $^{2,9}$. The rapid degradation and destruction of tropical forests ${ }^{12-13}$ and the enormous impact this may have on global biodiversity ${ }^{1}$, carbon and water cycling and climate feedbacks ${ }^{14}$ makes understanding the mechanisms maintaining and structuring their diversity imperative.

There is compelling evidence that natural enemies, including insect herbivores and fungal and oomycete pathogens (hereafter referred to collectively as pathogens), regulate many plant populations in the tropics ${ }^{7,15-17}$ and elsewhere ${ }^{18-19}$. Transmission of natural enemies is more effective between plants growing in areas of high conspecific density, making them less likely to survive. The Janzen-Connell hypothesis suggests that this negative density dependence (NDD) will promote plant community diversity by preventing dominant species from competitively excluding other species $^{3-4}$. This hypothesis is one of the most widely-invoked explanations for species coexistence, and ultimately high diversity, in plant communities.

While numerous studies have revealed NDD in plant communities ${ }^{6,8,20}$, there is considerably less empirical support for the contention that this will translate into enhanced community diversity ${ }^{2,9}$. A key study ${ }^{5}$ in Panama documented NDD at the seed to seedling transition in a suite of 53 species, and linked this NDD to increased community diversity. However, the causes of this NDD were not identified. While reduced herbivory by vertebrates can alter the composition of tropical plant 
communities $^{21-23}$, such effects rarely show NDD, and insect herbivores and pathogens are widely regarded as the most likely causes of NDD leading to enhanced plant diversity $^{2,9,24}$. Despite this, studies demonstrating a causal link between insect and pathogen mediated NDD and plant community diversity are lacking.

We compared plant community diversity for seeds and recruiting seedlings in a tropical forest in Belize, Central America, and investigated whether experimentally excluding natural enemies decreased plant diversity, as predicted by the JanzenConnell hypothesis. The effective number of species (measured as the inverse Simpson's dominance index, 1/D) among seedlings recruiting in un-manipulated (control) plots was significantly higher than among seeds falling in adjacent seed-fall $\operatorname{traps}\left(\Delta \log (1 / \mathrm{D})=0.69 \pm \mathrm{se}=0.058, t_{107}=11.91, P<0.001\right)$ corresponding to a doubling of the effective number of plant species at the seed to seedling transition. To determine whether insect herbivores or pathogens could be contributing to this increase in diversity we compared the diversity of seedlings growing in control plots (sprayed weekly with water) to plots where we suppressed either insects by spraying an insecticide $\left(\right.$ Engeo $\left.^{\circledR}\right)$, or pathogens by spraying one of two fungicides, Amistar ${ }^{\circledR}$ or Ridomil $^{\circledR}$. Each of the pesticide treatments reduced species diversity, but the effects were only statistically significant for the fungicide Amistar ${ }^{\circledR}$ (Fig $1 a, t_{105}=-2.45 P=$ 0.016 ), which reduced the effective number of species by approximately $16 \%$. This result clearly implicates pathogenic fungi in promotion of seedling diversity.

Two other clear changes in the plant community at the seed to seedling transition were a shift in species abundances, and a shift in species composition. These trends were also affected by pesticide treatments. Insecticide treatment increased the total number of recruiting seedlings by a factor of 2.7 compared to the control (Fig $1 b ; t_{105}$ 
$=7.67, P<0.001)$, demonstrating that plant-feeding insects are a major cause of mortality at this life stage. While Amistar ${ }^{\circledR}$ enhanced seedling recruitment, this effect was marginally non-significant $\left(t_{105}=1.81, P=0.074\right)$. Dissimilarity in species composition between the seeds and seedlings, measured using the Morisita-Horn index $\left(R_{h}\right)^{25}$, was about $87 \%$ in the control plots (Fig 1c). Treating seedlings with insecticide dramatically and significantly reduced this dissimilarity $\left(t_{105}=-7.86, P<\right.$ 0.001). The fungicide $\left(\right.$ Amistar $^{\circledR}$ and Ridomil ${ }^{\circledR}$ ) treatments did not reduce the dissimilarity to seeds significantly, but nevertheless the dissimilarity between the species compositions of the fungicide-treated plots and the control plots was about 20\% (Extended Data Figure 1). Overall, our results suggest that insects disproportionately kill certain plant species, reducing their abundances during the transition from seeds to seedlings. Insects thus strongly influence the structure of plant communities in this forest; however by doing so relatively independently of plant density, their net effect on plant species diversity is small.

For 18 species, sufficient data were available to conduct a formal test for NDD (see Methods Analysis). The slope of the relationship between the log number of seeds and the log number of seedlings in the control plots was less than one in 13 of the 18 species, and significantly $<1$ for three of these (Fig. 2a; Table S1), indicating $\mathrm{NDD}^{5}$. Furthermore, the mean slope across species was significantly $<1$ in the control treatment $\left(t_{48}=-3.23, P=0.002\right)$, suggesting that NDD is widespread, as has been found in previous studies of the seed to seedling transition in tropical forests ${ }^{5}$. Suppressing fungi using the fungicide Amistar ${ }^{\circledR}$ reduced the strength of NDD in seven species, and increased the mean slope significantly $\left(t_{48}=2.09, P=0.042\right)$, so that the mean slope was no longer significantly different from one (Fig. $2 \mathrm{c} ; t_{47}=-1.35, P=$ 0.183). Ridomil ${ }^{\circledR}$ and Engeo ${ }^{\circledR}$, both had smaller effects on the strength of NDD, with 
the mean slope remaining significantly less than one in both treatments (Fig 2). Thus, the significant effects of fungal pathogen exclusion on seedling diversity shown in Fig 1 can be causally linked to a reduction in the incidence and magnitude of NDD.

The strength of NDD in unmanipulated plots was highest in the species that were most abundant as seeds (Fig. $3 \mathrm{a} ; t_{16}=-2.75, P=0.015$; Extended Data Table 1). Greater NDD might be detected in more abundant species because they occur at high enough densities to facilitate transmission of insects and pathogens, whereas the densities of less abundant species are too low to trigger density-dependence.

Alternatively, common species may be more susceptible to density-dependent processes because pests and diseases adapt to exploit the most abundant resources, but this runs counter to the findings of two recent studies which assessed plant abundance at larger spatial scales ${ }^{16,26}$. Nevertheless, by reducing the survival of common species disproportionately, NDD may have increased the diversity of recruits more than expected from the average NDD effect. Both fungicide treatments weakened the relationship between NDD and abundance markedly (Figs 3c, 3d; Amistar ${ }^{\circledR}: t_{48}=$ 2.48, $P=0.017$; Ridomil $\left.{ }^{\circledR}: t_{48}=2.51, P=0.016\right)$ but insecticide had a smaller effect (Fig. $3 \mathrm{~b}: t_{48}=1.16, P=0.250$ ). By weakening NDD, especially in abundant species, fungicide application may have removed one mechanism for enhancing diversity at the seed to seedling transition, leading to the significantly lower seedling diversity observed in the Amistar ${ }^{\circledR}$ treatment.

As a final evaluation of the contribution of the observed NDD to enhancing the diversity of recruiting seedlings, we used a simulation approach. Changes in community diversity and composition across the seed to seedling transition and following the exclusion of natural enemies could result from either NDD or trade-offs 
between seed production and allocation to defence against insects and fungi. To distinguish these two possibilities we used models fitted to the 18 most abundant species to simulate communities under three scenarios (see Methods). In the first scenario (low-density survival), per capita recruitment was independent of seed density and equal to that expected under each treatment in the absence of conspecific neighbours. This scenario reflects survival when NDD is not operating. In a second scenario (mean-density survival), per capita recruitment was also independent of seed densities, but set to the mean survival rate observed for each species, consistent with previous studies ${ }^{5}$.In the third scenario (NDD survival), per capita recruitment was dependent on both pesticide treatment and seed density. Simulations under the lowdensity survival scenario greatly underestimated the effective number of species in the control plots (Fig 4a). Adding NDD to the simulations replicated the observed data better. Total seedling abundance was also overestimated (Fig 4b) and dissimilarity in species composition underestimated (Fig 4c) in the control and insecticide treatments in the absence of NDD. The mean-density scenario also underestimated species richness in the control plots but otherwise predicted community size, diversity and composition well (Extended Data Figure 2). Overall, these simulations confirm that pathogen-mediated NDD is responsible for increasing the diversity of seedlings.

While individual components of the Janzen-Connell hypothesis have been tested repeatedly since its formulation more than 40 years ago ${ }^{3-4}$, experimental tests of the key overall hypothesis that natural enemies cause NDD and thus promote species coexistence and enhance species diversity are rare. In one such study, Theimer and colleagues $^{21}$ found no evidence that vertebrate herbivores increased diversity or caused NDD. However, while vertebrates have occasionally been implicated as drivers of $\mathrm{NDD}^{27-29}$, the primary causes of NDD are thought to be insects and 
pathogens $^{2,9,24}$. The results presented here build on existing evidence for widespread NDD in tropical plant communities ${ }^{5-6,8,20,26}$ by establishing the cause of NDD, and by linking it to increased plant species diversity, as suggested by the Janzen-Connell hypothesis.

Our experiments highlight that both insect herbivores and pathogens help structure tropical plant communities at the early stages of community assembly and provides support for a pivotal role for natural-enemy-mediated NDD in maintaining species diversity in this tropical forest. While the magnitude of the NDD we observed was relatively small, this study was conducted over a relatively short time scale (17 months) in a tropical forest of relatively low plant species diversity (about 320 tree species have been recorded in the reserve $\mathrm{e}^{30}$ ). It is likely that the effects of NDD will accumulate over time, and may be stronger in other, more species-rich forests. Indeed, similar experiments in other forests are now needed to evaluate the generality of Janzen-Connell hypothesis as an explanation for variations in the species diversity of tropical plant communities.

\section{Methods Summary}

We established 36 sampling stations within a 1 ha area in deciduous/ semievergreen seasonal forest in the Chiquibul Forest Reserve, Belize. Each station had three seed traps and four seedling plots. Plots were randomly assigned to four treatments: control (sprayed with water), insecticide $\left(\right.$ Engeo $\left.^{\circledR}\right)$, or one of two fungicides (Amistar ${ }^{\circledR}$ or Ridomil $^{\circledR}$ ), applied weekly for 17 months. We recorded numbers of seeds from each species collected weekly in each trap. Number and identities of seedlings germinating in each plot were recorded monthly during the peak recruitment period (April - August) and every 2-4 months otherwise. We 
compared the total number of individuals and their diversity (inverse Simpson's dominance index, $1 / D$ ) between seeds and seedlings in the control plot and among pesticide treatments using mixed-effects models. We also compared dissimilarity in species composition between seeds and seedlings (Morisita-Horn dissimilarity index) among pesticide treatments. In the absence of NDD, a slope of 1 is expected for the

relationship between log number of seeds and log number of seedlings ${ }^{5}$. We estimated this slope and the effect of pesticide treatments for 18 species. To determine the average effect of density and the effect of overall species abundance, we modelled the standardised slopes (see Methods) of each species and pesticide treatment combination as a function of sample size, log total seed abundance and pesticide treatment, using a mixed-effects model. Finally, to determine whether NDD could generate observed differences in communities among treatments, we used the models of the 18 species to simulate communities, assuming survival to be either density dependent or density independent, based on the establishment probability expected in the absence of conspecific neighbours. We calculated abundance, diversity and dissimilarity based on 1000 simulations for each scenario and compared the mean and $95 \%$ confidence intervals of the observed data to those derived from the simulations.

\section{Acknowledgements}

This paper is dedicated to the memory of Nicodemus ('Chapal') Bol. We thank the staff at the Las Cuevas Research Station (the late Nicodemus Bol, Celia Bol, Matthew Bol and Jimmy Boucher) for their help throughout this project. Ricardo Cocomb, Ed Miles, Claire Rasell, Mike Senior, Tom Swinfield and Ole Theisinger provided field assistance, and Håvard Rue provided advice on implementing measurement error models in INLA. This research was funded by the Natural 
Environment Research Council (NERC; standard grant NEDO10721/1) and SG was funded by grant 126296 from the Academy of Finland.

\section{Author Contributions}

O.T.L., R.P.F. and S.J.G. conceived the project and obtained funding. R.B., R.E.G., S.G., O.T.L., L.N. and C.E.A. established fieldwork design and protocols, and carried out the fieldwork with advice from R.P.F. and S.J.G. Data analyses was carried out by R.B. with input from R.P.F. and O.T.L. R.B. wrote the first draft of the manuscript and all authors contributed to discussing the results and editing the manuscript.

\section{Author Information}

Data sets and $R$ code for performing analyses are available from the authors. Correspondence should be addressed to O.T.L. (owen.lewis@zoo.ox.ac.uk).

1 Gibson, L. et al. Primary forests are irreplaceable for sustaining tropical biodiversity. Nature 478, 378-381, doi:10.1038/nature10425 (2011).

2 Wright, S. J. Plant diversity in tropical forests: a review of mechanisms of species coexistence. Oecologia 130, 1-14, doi:10.1007/s004420100809 (2002)

3 Janzen, D. H. Herbivores and the number of tree species in tropical forests. Am. Nat. 104, 501-528, doi:10.1086/282687 (1970).

4 Connell, J. H. in Dynamics of Numbers in Populations eds P.J. den Boer \& G.R. Gradwell) 298-312 (PUDOC, Wageningen, The Netherlands, 1971). 
5 Harms, K. E., Wright, S. J., Calderón, O., Hernández, A. \& Herre, E. A. Pervasive density-dependent recruitment enhances seedling diversity in a tropical forest. Nature 404, 493-495, doi:10.1038/35006630 (2000).

6 Metz, M., Sousa, W. \& Valencia, R. Widespread density-dependent seedling mortality promotes species coexistence in a highly diverse Amazonian rain forest. Ecology 91, 3675-3685, doi:10.1890/08-2323.1 (2010).

7 Bagchi, R. et al. Testing the Janzen-Connell mechanism: pathogens cause overcompensating density dependence in a tropical tree. Ecol. Lett. 13, 12621269, doi:10.1111/j.1461-0248.2010.01520.x (2010).

8 Comita, L. S. \& Hubbell, S. P. Local neighborhood and species' shade tolerance influence survival in a diverse seedling bank. Ecology 90, 328-334, doi: 10.1890/08-0451.1 (2009).

9 Terborgh, J. Enemies Maintain Hyperdiverse Tropical Forests. Am. Nat. 179, 303-314, doi:10.1086/664183 (2012).

10 Kobe, R. K. \& Vriesendorp, C. F. Conspecific density dependence in seedlings varies with species shade tolerance in a wet tropical forest. Ecol. Lett. 14, 503-510, doi:10.1111/j.1461-0248.2011.01612.x (2011).

11 Chesson, P. Mechanisms of maintenance of species diversity. Annu. Rev. Ecol. Syst. 31, 343-366 (2000).

12 Curran, L. M. et al. Lowland forest loss in protected areas of Indonesian Borneo. Science 303, 1000-1003, doi:10.1126/science.1091714 (2004). 
13 Achard, F. et al. Determination of deforestation rates of the world's humid tropical forests. Science 297, 999-1002, doi:10.1126/science.1070656 (2002).

14 Bonan, G. B. Forests and climate change: Forcings, feedbacks, and the climate benefits of forests. Science 320, 1444-1449, doi:10.1126/science.1155121 (2008).

15 Bell, T., Freckleton, R. P. \& Lewis, O. T. Plant pathogens drive densitydependent seedling mortality in a tropical tree. Ecol. Lett. 9, 569-574, doi:10.1111/j.1461-0248.2006.00905.x (2006).

16 Mangan, S. A. et al. Negative plant-soil feedback predicts tree-species relative abundance in a tropical forest. Nature 466, 752-755, doi:10.1038/nature09273 (2010).

17 Swamy, V.\& Terborgh, J. W. Distance-responsive natural enemies strongly influence seedling establishment patterns of multiple species in an Amazonian rain forest. J. Ecol. 98, 1096-1107, doi:10.1111/j.1365-2745.2010.01686.x (2010).

18 Bever, J. D. Feedback between plants and their soil communities in an old field community. Ecology 75, 1965-1977, doi:10.2307/1941601 (1994).

19 Packer, A. \& Clay, K. Soil pathogens and spatial patterns of seedling mortality in a temperate tree. Nature 404, 278-281, doi:10.1038/35005072 (2000).

20 Webb, C. O. \& Peart, D. R. Seedling density dependence promotes coexistence of Bornean rain forest trees. Ecology 80, 2006-2017, doi:10.1890/0012-9658 (1999). 
21 Theimer, T. C., Gehring, C. A., Green, P. T. \& Connell, J. H. Terrestrial vertebrates alter seedling composition and richness but not diversity in an Australian tropical rain forest. Ecology 92, 1637-1647, doi:10.1890/10-2231.1 (2011).

22 Leigh, E. G., Wright, S. J., Herre, E. A. \& Putz, F. E. The decline of tree diversity on newly isolated tropical islands - a test of a null hypothesis and some implications. Evol. Ecol. 7, 76-102, doi:10.1007/bf01237735 (1993).

23 Terborgh, J. et al. Tree recruitment in an empty forest. Ecology 89, 1757-1768 (2008).

24 Hammond, D. S. \& Brown, V. K. in Dynamics of Tropical Communities. eds D.M. Newbery, H.H.T Prins, \& N.D Brown) 51-78. (Blackwell, 1998).

25 Horn, H. S. Measurement of "overlap" in comparative ecological studies. The American Naturalist 100, 419-424, doi:10.2307/2459242 (1966).

26 Comita, L. S., Muller-Landau, H. C., Aguilar, S. \& Hubbell, S. P. Asymmetric density dependence shapes species abundances in a tropical tree community. Science 329, 330-332, doi:10.1126/science.1190772 (2010).

27 Bagchi, R. et al. Impacts of logging on density-dependent predation of dipterocarp seeds in a southeast Asian rainforest. Philos. Trans. R. Soc. Lond. B Biol. Sci. 366, 3246-3255, doi:10.1098/rstb.2011.0034 (2011).

28 Paine, C. E. T. \& Beck, H. Seed predation by Neotropical rain forest mammals increases diversity in seedling recruitment. Ecology 88, 3076-3087, doi:10.2307/27651473 (2007). 
29 Norghauer, J., Malcolm, J., Zimmerman, B. \& Felfili, J. An experimental test of density- and distant-dependent recruitment of mahogany (Swietenia macrophylla) in southeastern Amazonia. Oecologia 148, 437-446, doi:10.1007/s00442-006-0395-2 (2006).

30 Bridgewater, S. G. M. et al. A preliminary checklist of the vascular plants of the Chiquibul Forest, Belize. Edinb. J. Bot. 63, 269-321, doi:10.1017/s0960428606000618 (2006).

\section{Figure Legends}

Figure 1: Suppression of insects and pathogens alters seedling community composition and diversity, respectively. The figure shows effects of insecticide $\left(\right.$ Engeo $^{\circledR}$ ) and two fungicides (Amistar ${ }^{\circledR}$ and Ridomil $^{\circledR}$ ) on (a) the mean effective number of species recruiting as seedlings; (b) the mean seedling abundance (log scale) summed across all species; (c) the mean dissimilarity in species composition for seedlings under each treatment compared to seeds in adjacent seed traps. The error bars represent the $95 \%$ confidence intervals of the mean across the 36 stations.

Figure 2: Recruitment across the seed to seedling transition showed NDD in the control, but spraying with the fungicide Amistar ${ }^{\circledR}$ removed this NDD. (a) The relationship between log number of recruits and log number of seeds will have a slope of 1 without NDD (dotted line). For Terminalia amazonia, the slope was lowest (and $<1$ ) in the control; treatment with fungicides but not insecticides increased the slope. (b) The standardised NDD effect is significantly $<1$ across 18 species in the control treatment, indicating prevalent NDD. Spraying with Amistar ${ }^{\circledR}$, but not other pesticides, removed this effect. Error bars are 95\% confidence intervals. 
Figure 3: Negative density dependence is strongest in species that are most abundant as seeds. The relationship between log seed abundance and the strength of NDD is shown for the 18 species analysed. The relationships are shown for (a) the control plots sprayed with water; (b) plots sprayed with the insecticide Engeo ${ }^{\circledR}$; (c) plots sprayed with the fungicide Amistar ${ }^{\circledR}$ and (d) plots sprayed with an alternative fungicide Ridomil ${ }^{\circledR}$. The bold lines are the relationships fitted with a linear mixed effects model, with the $95 \%$ confidence intervals indicated by the shaded areas.

Figure 4: Including NDD in model simulations reproduces the observed diversity patterns while excluding NDD underestimates diversity in the control and insecticide treatments. The observed diversity in each treatment was compared with those simulated either assuming a constant survival for each species (low-density survival) or negatively density dependent survival (NDD survival). The error bars are $95 \%$ confidence intervals of the mean extracted from models fitted to the data (observed) or the $95 \%$ quantile (simulations) from 1000 simulations under each scenario. 


\section{Methods}

\section{Field survey}

Our field site was close to the Las Cuevas Research Station in SW Belize (16 43' 53 "' $\mathrm{N}, 88^{\circ} 59^{\prime} 11^{\prime \prime} \mathrm{W}$ ) at $450 \mathrm{~m}$ elevation on limestone geology within the 170,000 ha Chiquibul Forest Reserve protected area. This area was subjected to light selective logging in the mid- $20^{\text {th }}$ century, but has a relatively intact flora and fauna. There is a marked dry season, typically from February to May, with annual rainfall approximately 1500 to $1800 \mathrm{~mm}^{31}$. We established 36 sampling stations on the forest floor, positioned at $20 \mathrm{~m}$ intervals on a 120 x $120 \mathrm{~m}$ grid. Each station comprised seven $1 \mathrm{~m}^{2}$ quadrats, placed as close together as possible while avoiding trees and large rocks. Three of the quadrats at each station were randomly selected as locations for $1 \mathrm{~m}^{2}$ seed traps made from $1 \mathrm{~mm}$ mesh fibreglass netting, suspended $80 \mathrm{~cm}$ above the ground using PVC poles. The remaining quadrats were cleared of existing seedlings and assigned at random to one of three enemy exclusion treatments or to a control treatment. Two fungicide treatments were used: Amistar ${ }^{\circledR}$ (Syngenta Ltd, Basel, Switzerland; active ingredient: azoxystrobin), which has broad-spectrum systemic activity against a range of plant pathogenic fungi, and Ridomil Gold ${ }^{\circledR} \mathrm{MZ}$ 68WP (Syngenta Ltd, Basel, Switzerland; active ingredients: mancozeb and metalxyl) which protects plants from infection by oomycetes and fungi. The insecticide used was Engeo ${ }^{\circledR}$ (Syngenta Ltd, Basel, Switzerland; active ingredient: thiamethoxam), which provides both systemic and contact protection against a range of insects. Pesticides were applied weekly with a hand-mister, following the manufacturers' guidelines (0.005 $\mathrm{g}$ of Amistar ${ }^{\circledR}, 0.25 \mathrm{~g}$ of Ridomil Gold ${ }^{\circledR}$, or $0.0025 \mathrm{~mL}$ of Engeo ${ }^{\circledR}$, in each case dissolved in $50 \mathrm{~mL}$ of water). Control plots were sprayed with $50 \mathrm{~mL}$ of water at the same time as pesticide applications. Treatments began in July 2007 
except for the Engeo ${ }^{\circledR}$ application which began in April 2008. All treatments were applied weekly until September 2009. Only data from April 2008 onwards (during which all treatments were applied) were used in the analyses presented here.

Seeds were collected weekly from the traps; damaged or inviable seeds were discarded and the remaining seeds were counted and identified to species level, where possible, or as morphospecies. A subset of the seeds from each species and morphospecies were placed on moist tissue paper in seed germination trays. We photographed examples of all seed and seedling morphospecies to (i) match seeds to seedlings in cases where species identification was not possible; (ii) ensure consistent classification throughout the experiment; and (iii) facilitate subsequent plant identification. In this way we matched $97 \%$ of the individual seeds collected in our study to seedlings.

We censused the seedling plots for new seedlings every month during the peak period of fruiting and recruitment (April-August) and less frequently (every 2-4 months) during the rest of the year. At each census, all new seedlings were tagged and identified to species or morphospecies. Unidentified seedlings were photographed. By comparing these photographs to seedlings germinated from collected seeds we were able to match $90 \%$ of the observed seedlings to seeds.

To confirm that the significant effects of insecticide treatment were a consequence of reduced attack from insects rather than a direct effect of Engeo ${ }^{\circledR}$ on plant survival $^{32}$, we set up experiments in May 2010 where a subset of the focal plant species (Stemmadenia donnell-smithii $(n=60)$, Cordia alliodora $(n=80)$, Cryosophila stauracantha $(n=70)$, Combretum laxum/fruticosum $(n=70)$, Terminalia amazonia $(n=100)$ and Forsteronia sp. $(n=70)$ were grown from seed at high density under 
insect-free conditions, and with Engeo ${ }^{\circledR}$ treatment. Freshly-collected seeds were sown into 60 seed trays ( $36 \mathrm{~cm} \mathrm{~L} \mathrm{x} 24 \mathrm{~cm} \mathrm{~W} \mathrm{x} 5 \mathrm{~cm} \mathrm{D)} \mathrm{filled} \mathrm{with} \mathrm{locally-collected} \mathrm{soil}$ that had been sorted to remove large stones and roots. Each tray was divided into six sections, with seeds of each species sown into one section. Trays were enclosed in a bag made from insect-proof nylon netting to exclude insects. The netting was raised above the surface of the tray to allow seedlings to grow. For the shadehouse experiment, 30 trays were placed in randomly-allocated positions on raised benches in a small forest gap, covered with waterproof shade netting. For the field experiment 30 trays were placed on the forest floor in a randomised grid design, spaced by $200 \mathrm{~cm}$. Trays in the shadehouse were watered regularly (every $\sim 2 / 3$ days). Half of the trays (chosen at random) in both experiments were sprayed weekly with $0.0025 \mathrm{~mL} \mathrm{~m}^{-2}$ of Engeo ${ }^{\circledR}$ using a hand mister. The remaining trays were sprayed with an equal volume of water. Germinating and surviving seedlings were censused after eight weeks (shadehouse experiment) or seven weeks (field experiment). We analysed the number of seedlings at the end of the experiment as a function of insecticide treatment using generalised linear models for each species, assuming a negative binomial distribution for the errors. No significant $(P<0.05)$ effects of Engeo ${ }^{\circledR}$ on survivorship were documented in any species in either experiment (see Extended Data Table 2).

\section{Analysis}

We calculated the total number of seeds or seedlings observed in each seedling plot $(N)$ and the reciprocal of the Simpson's Dominance Index $\left(1 / D, D=\sum_{k}^{s} p_{k}^{2}\right.$, where $p_{k}$ is the proportional abundance of species $k$ in a community with $s$ species) as a measure of the effective number of species ${ }^{33}$. We quantified differences in species composition among treatments by calculating the Morisita-Horn index of dissimilarity $\left(R_{h}\right)^{25}$ 


$$
R_{h_{i j}}=1-\frac{2 \cdot \sum\left(N_{i k} \cdot N_{j k}\right)}{\left(\sum_{k}^{S} N_{i k}^{2} /\left(\sum_{k}^{S} N_{i k}\right)^{2}+\sum_{k}^{S} N_{j k}^{2} /\left(\sum_{k}^{S} N_{j k}\right)^{2}\right) \cdot \sum_{k}^{S} N_{i k} \cdot \sum_{k}^{S} N_{j k}}
$$

between the seed traps and all the seedling plots at each station. Results were qualitatively unchanged using other diversity and dissimilarity metrics (e.g. Shannon's diversity index and the Bray-Curtis index of dissimilarity, see Extended Data Tables 3 and 4). We compared these metrics between control plots and seed traps and among pesticide treatments (control, insect exclusion with Engeo ${ }^{\circledR}$, true fungi exclusion with Amistar ${ }^{\circledR}$ or oomycete and true fungi exclusion with Ridomil $^{\circledR}$ ), using linear mixed effects models (fitted using the $n l m e$ package ${ }^{34}$ in $\mathrm{R} 3.0 .1^{35}$ ) with different intercepts for the stations included as a normally-distributed random effect. We assumed a Gaussian error distribution for the models of $N$ (log transformed), $1 / D$ (log transformed) and dissimilarity (logit transformed). There was evidence of heteroscedascity in the residuals of the models of $1 / \mathrm{D}$ and $R_{h}$, so this was accounted for by explicitly modelling the variance as a function of pesticide treatment (for 1/D) or as an exponential function of the expected values (for $R_{h}$ ).

We used these models to test three hypotheses:

1) Diversity is greater among seedlings than among seeds.

2) Excluding natural enemies with pesticides decreases diversity.

3) Excluding natural enemies with pesticides alters species composition.

For a subset of species we examined the effects of pesticides, seed density and their interaction on seedling recruitment at the level of individual species. For this analysis, we selected all 18 species that met two criteria: (i) seeds and or seedlings of these species were recorded at $\geq 5$ stations (the sets of stations with seeds and seedlings did not have to overlap), and (ii) mean seed density varied at least three-fold 
among stations. The species that met these criteria are listed in Table S1. The relationship between the number of seeds in plot $i$ at station $j, N_{0, i j}$, and the expected number of recruits, $N_{l, i j}$ can be described by the equation ${ }^{5}$ :

$$
N_{1, i j}=\exp (\alpha) \cdot N_{0, i j}^{\beta}
$$

where $\exp (\alpha)$ is the ratio of seedlings to seeds at low density $\left(N_{0, i j}=1\right)$. The parameter $\beta$ is 1 if survival is independent of conspecific density and less than 1 when this ratio is reduced at high density (i.e. NDD). Because we did not measure the seed rain in the seedling plots at each station $j$ directly, $N_{0, i j}$ has to be estimated from the adjacent seed traps at station $j$ instead. Ignoring the error in these estimates of $N_{l, i j}$ biases the estimation of $\beta$ towards $0^{36}$, and therefore overestimates the importance of NDD. To overcome this potential bias, we modelled $N_{0}$ and $N_{1}$ jointly as

$\widehat{N}_{0, i j}=\operatorname{NegBin}\left(\lambda_{j}, \kappa_{0}\right) ; \lambda_{j} \sim \operatorname{lognorm}\left(\bar{\lambda}, \sigma^{2}\right)$

$\widehat{N}_{1, i j L}=N \operatorname{eg} \operatorname{Bin}\left(\exp \left(\alpha_{L}\right) \cdot \mathrm{N}_{0, \mathrm{ij}}^{\beta_{L}}, \kappa_{1, L}\right)$

where both $\widehat{N}_{0, i j}$ (the number of seeds in plot $i$ at station $j$ ) and $\widehat{N}_{1, i j}$ (the number of recruits in plot $i$ at station $j$ ) were drawn from negative binomial distributions defined by the expected number of individuals and stage $(t, t=0,1)$ and treatment $(L)$ specific size or overdispersion parameters, $\kappa_{t, L}$. The expected number of seeds in the plots at station $j$ is $\lambda_{j}$ and the $\lambda_{j}$ were drawn from a lognormal distribution with mean $\bar{\lambda}$ and variance $\sigma^{2}$. The number of seeds falling in the seedling plots is treated as missing data which need to be imputed from the seed trap data collected at the same station. The parameters $\alpha_{L}$ and $\beta_{L}$ correspond to the low density survival rate and effect of density on recruitment under treatment $L$ as described by equation 2 . This hierarchical model was fitted using the INLA package ${ }^{37}$ in R $3 \cdot 0.1^{35}$. 
We used estimates of $\beta_{L}$ from these models to test two hypotheses for each species.

1) Survival is negatively density dependent $\left(\beta_{\text {control }}<1\right)$.

2) Natural enemies cause the observed negative density dependence, so that applying pesticides weakens the relationship between seed density and $\operatorname{survival}\left(\beta_{\text {control }}<\beta_{\text {pesticide })}\right.$

We tested whether the estimates of $\beta$ across the 18 species were significantly different from 1 in the control treatment and whether they varied among pesticide treatments and with the logarithm of the seed abundance $\left(N_{0, k}\right)$ of each species, $k$. This was achieved by fitting a linear mixed-effects model to standardised estimates of $\beta$ (standardised as $\left.\hat{\beta}_{k L}=\left(\beta_{k L}-1\right) / 2 \cdot S D_{\beta_{k L}}\right)$ with species included as a random effect. Sample size (the number of stations where each species was collected either as seeds or seedlings, $J$ ) was included in the model as a covariate to control for effects of sample size on parameter estimates. The model can be described as

$$
\begin{gathered}
\hat{\beta}_{k L}=\gamma_{0}+\gamma_{1} \cdot J+\gamma_{2, L}+\gamma_{3} \cdot \log \left(N_{0 . k}\right)+\gamma_{4, L} \cdot \log \left(N_{0, k}\right)+b_{k}+\epsilon_{k L} \\
b_{k} \sim \operatorname{Norm}\left(0, \sigma_{b}\right) ; \epsilon_{k L} \sim \operatorname{Norm}\left(0, \sigma_{\epsilon}\right)
\end{gathered}
$$

where the $\gamma$ represent the estimated fixed effects parameters, $b_{k}$ is the best linear unbiased predictor for species $k$ and $\varepsilon_{k L}$ is the error under treatment $L$ for species $k$. The parameters $\gamma_{2}$ (pesticide effect on mean NDD) and $\gamma_{4}$ (pesticide effect on the relationship between overall seed abundance and strength of NDD) are zero for the control treatment and represent the change in these parameters under each pesticide treatment compared to the control. An initial model suggested heteroscedasticity in the residuals, so the variance was modelled as an exponential function of the expected values. 
Finally, we tested whether the estimated effects of NDD and pesticides on recruitment of individual species could account for the observed differences in diversity among pesticide treatments. We used the parameters estimated in the 18 species-specific models to simulate new communities under three scenarios. For each species, the number of seeds in each trap was drawn from a negative binomial distribution with mean $\lambda_{j}$ and size $\kappa_{0}$. Under the "NDD survival" scenario, the number of seedlings in plots at station $j$ with treatment $L$ was drawn from a negative binomial distribution with mean $=\exp \left(\alpha_{1, L}+\beta_{1, L} \lambda_{j}\right)$ and size $=\kappa_{1, L}$. The "low-density survival" scenario assumed that survival was independent of seed density and was equal to the survival for each species within each pesticide treatment when density was 1 (i.e. when seedlings had no conspecific neighbours). We then calculated the effective number of species for the simulated communities at each station and treatment combination and extracted the means for each treatment. This procedure was repeated 1000 times and the median and $95 \%$ quantiles across the simulations were extracted under each scenario. A similar procedure was used to simulate communities expected under a third scenario where seed-to-seedling transition probabilities reflected those recorded at the mean seed density for each species. This was achieved by refitting the model to each species after fixing the value of all the $\beta_{L}$ to 1 and using this model for the simulations. We then calculated the mean total abundance, effective number of species and dissimilarity to species composition of the seeds in each treatment using the observed data for the 18 species. We compared these observed data to the simulations under all three scenarios.

31 Bridgewater, S. A Natural History of Belize. (University of Texas Press, 2012). 
32 Ford, K. A. et al. Neonicotinoid insecticides induce salicylate-associated plant defense responses. Proc. Natl. Acad. Sci. USA 107, 17527-17532, doi:10.1073/pnas.1013020107 (2010).

33 Jost, L. Entropy and diversity. Oikos 113, 363-375, doi:10.1111/j.2006.00301299.14714.x (2006).

34 Pinheiro, J. C. \& Bates, D. M. Mixed-Effects Models in S and S-Plus. (Springer Verlag, 2000).

35 R: A language and environment for statistical computing (R Foundation for Statistical Computing, Vienna, Austria, 2013).

36 Carroll, R. J., Ruppert, D., Stefanski, L. A. \& Crainiceanu, C. M.

Measurement Error in Nonlinear Models: A Modern Perspective. $2^{\text {nd }}$ edn, (Chapman \& Hall/CRC, 2006).

37 Rue, H., Martino, S. \& Chopin, N. Approximate Bayesian inference for latent Gaussian models by using integrated nested Laplace approximations. Journal of the Royal Statistical Society Series B-Statistical Methodology 71, 319-392, doi:10.1111/j.1467-9868.2008.00700.x (2009). 


\section{Extended Data Legends}

Extended Data Table 1: Coefficients from the model relating the strength of NDD (as measured by the standardised coefficient for seed density, $\beta$, from Equation 4 ) to treatment, log total seed abundance (standardised across species) and their interaction. Sample size is the number of stations at which each species was recorded, which is included to control for a possible effect of statistical power on the strength of NDD detected.

Extended Data Table 2: Coefficients from the negative binomial model fitted to the shade-house and field trials of effects of the insecticide Engeo ${ }^{\circledR}$ on seedling survival. Note that no species shows a significant effect of Engeo ${ }^{\circledR}$ treatment on survival (shaded rows).

Extended Data Table 3: Tests of pesticide effects on seedling species diversity using different diversity indices.

Extended Data Table 4: Tests of pesticide effects on dissimilarity in species composition, comparing seedlings germinating in plots to seeds falling in adjacent seed traps. Four alternative metrics of dissimilarity are presented.

Extended Data Figure 1: The mean dissimilarity in species composition (and 95\% confidence intervals), comparing seedlings recruiting in the control plots with seedlings in the pesticide treatments and with seeds falling into seed traps.

Extended Data Figure 2: A comparison of the observed seedling communities (Observed survival) to those simulated either fixing survival to the mean for each species in each treatment (Mean density survival) or allowing survival to be negatively density dependent (NDD survival). The simulated values are means and 95\% confidence intervals based on 1000 simulations for effective number of species, total abundance and community dissimilarity to seeds falling in adjacent traps, 
(a)

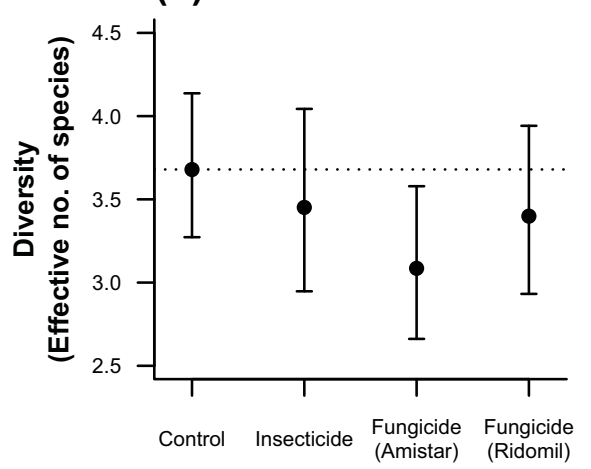

(b)

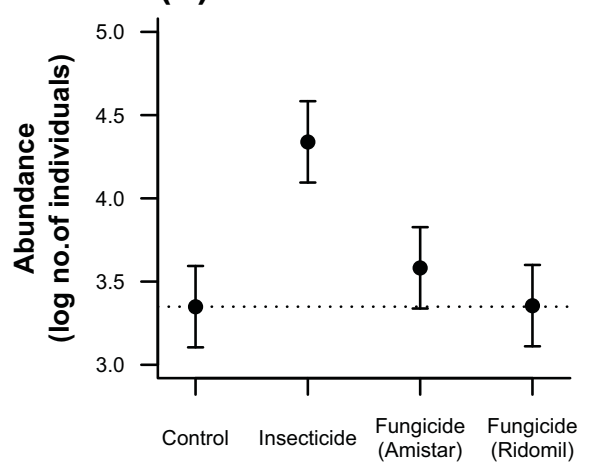

Treatment

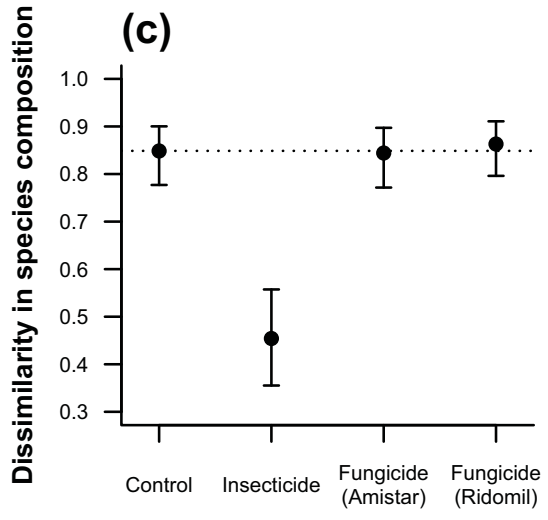



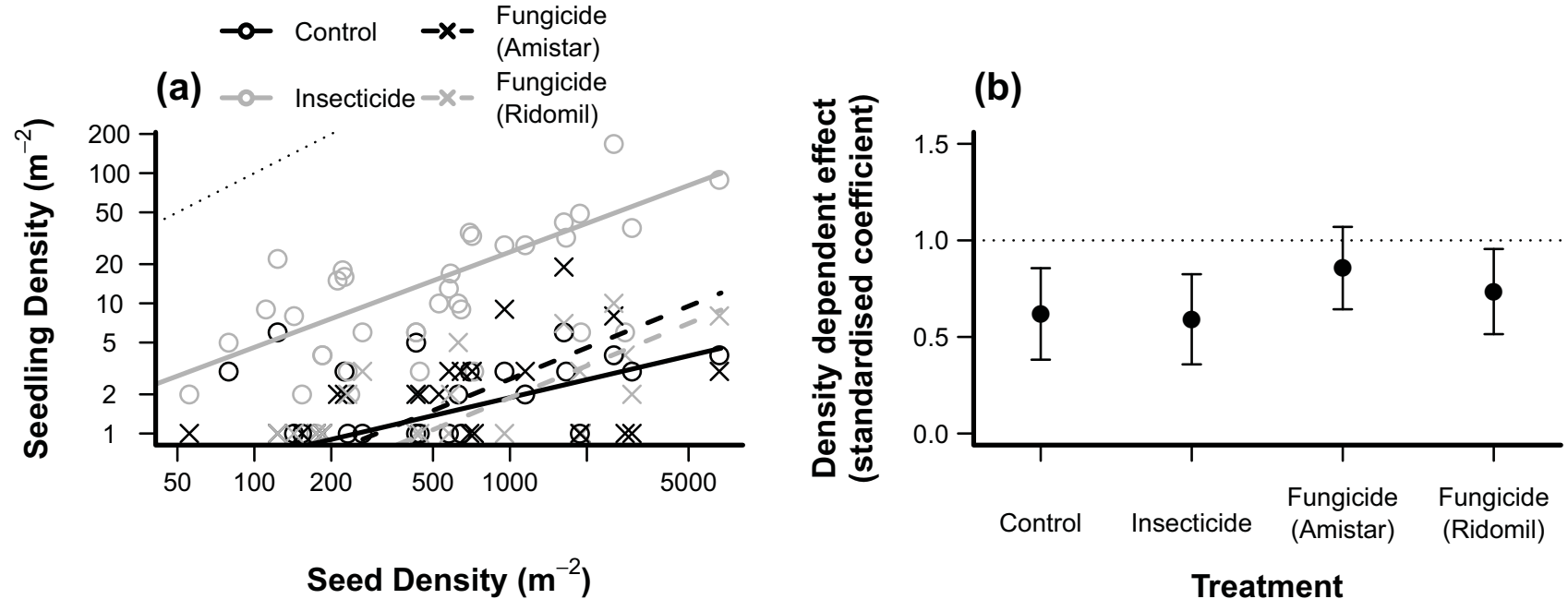
(a)

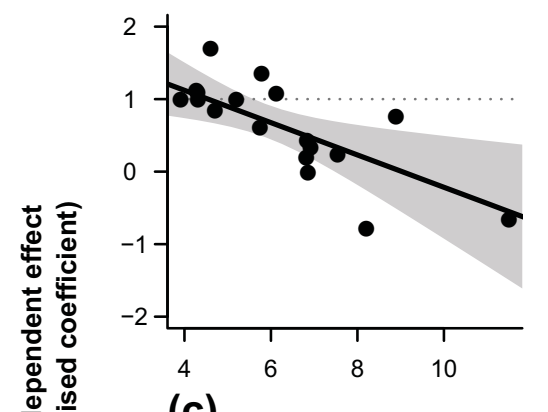

(c)

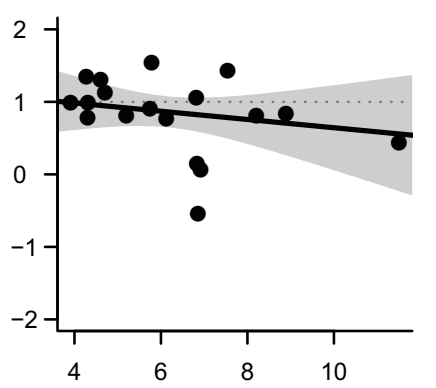

(b)

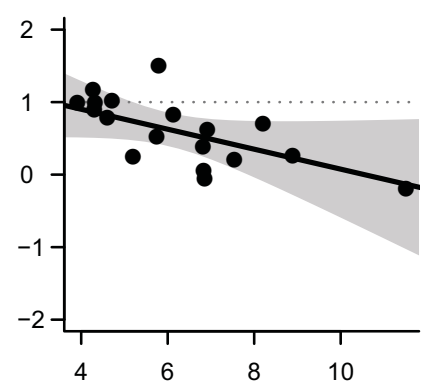

(d)

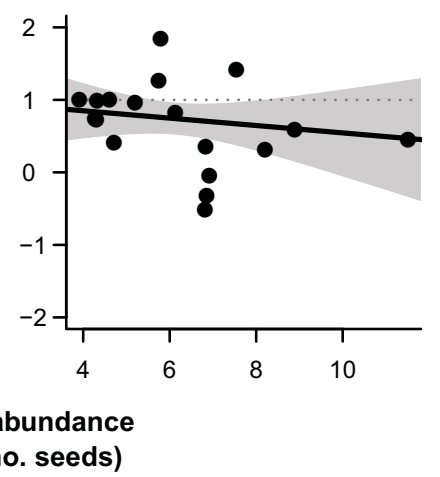




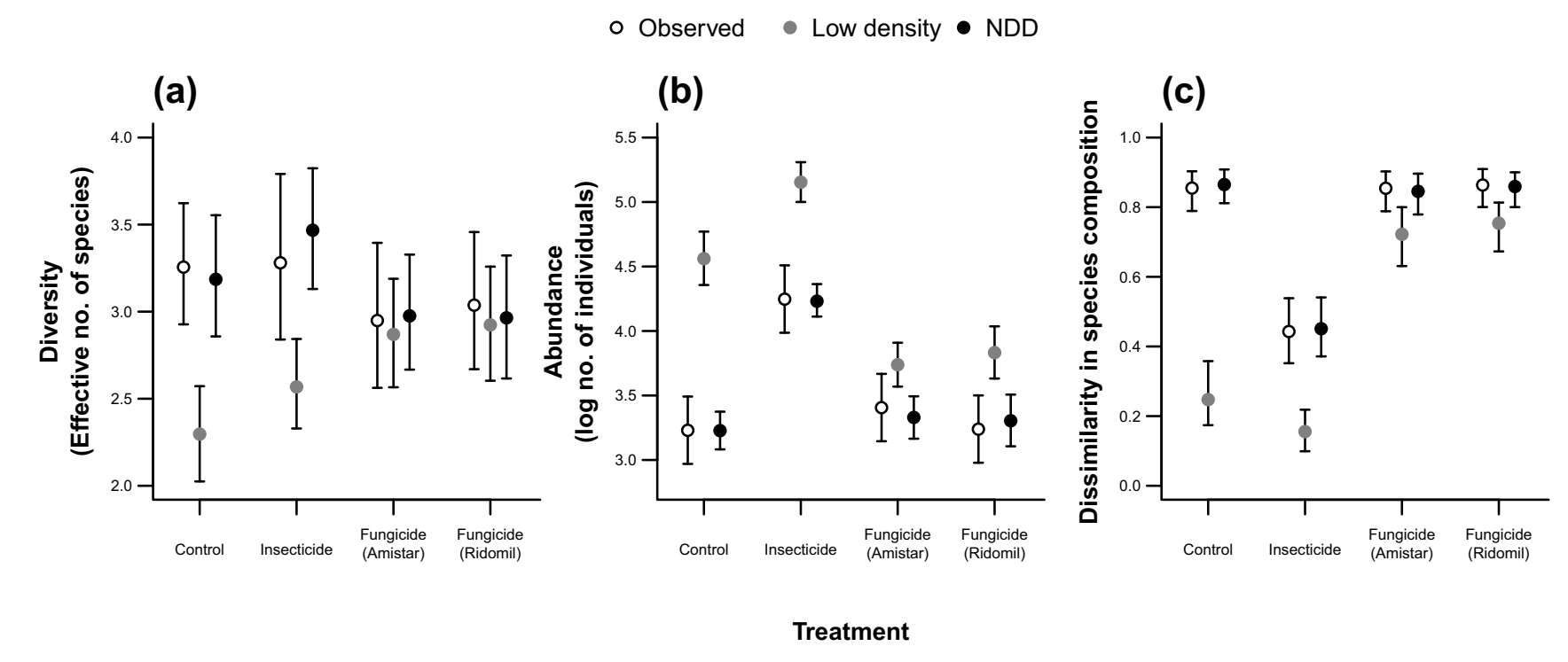

